\title{
Azimuthal Directivity of Fan Tones Containing Multiple Modes
}

\author{
Laurence J. Heidelberg* \\ NASA, Lewis Research Center \\ Cleveland, $\mathrm{OH}$ \\ Daniel L. Sutliff* \\ AYT Corporation \\ Brook Park, $\mathrm{OH}$
}

and

M. Nallasamy*

NYMA, Inc.

Brook Park, $\mathrm{OH}$

\section{ABSTRACT}

The directivity of fan tone noise is generally measured and plotted in the sideline or flyover plane and it is assumed that this curve is the same for all azimuthal angles. When two or more circumferential (m-order) modes of the same tone are present in the fan duct, an interference pattern develops in the azimuthal direction both in the duct and in the farfield. In this investigation two m-order modes of similar power were generated in a large low speed fan. Farfield measurements and a finite element propagation code both show substantial variations in the azimuthal direction. Induct mode measurement were made and used as input to the code. Although these tests may represent a worst case scenario, the validity of the current practice of assuming axisymmetry should be questioned.

\section{INTRODUCTION}

The farfield noise of turbofan engines and model scale fans are generally measured in a single plane that includes the fan axis of rotation. These measurements are then assumed to the same for all other planes through the fan axis. This axisymmetric assumption may not be justified for fan tone noise when more than one circumferential mode ( $\mathrm{m}$ order) is present. When two or more $\mathrm{m}$ orders are present in a duct they will interfere with each other in the circumferential direction. This induct interference pattern results in a still more complex pattern in the farfield. In this investigation two $\mathrm{m}$ orders of the blade passing frequency (BPF) are generated in a large low speed fan and both the farfield tone directivty and duct mode structure

1 Senior Member, AIAA. 
are measured. In addition, a finite element propagation code was used to project the induct mode data to the farfield. The motivation for using a code is that it could provide the complete 3-D farfield sound field from the mode measurements thus avoiding the tedious and difficult task of measuring in the farfield at all angles (both sideline and azimuthal).

Figure 1 shows the angular references used in this paper. The sideline angle is measured in a horizontal plane through the fan axis starting at the inlet axis. The azimuthal angle is measured in a plane perpendicular to the fan axis starting at the plane of the sideline measurement and moving in the direction of fan rotation. In this investigation azimuthal directivity was obtained by changing the spacial phase of one mode relative to the other, thus rotating the azimuthal pattern past the microphones instead of moving the microphones around the fan. The spacial phase was changed by clocking (rotating) the stator vane assembly in several small increments through one vane spacing.

\section{APPARATUS AND PROCEDURE}

\section{Test Bed}

These tests were conducted on the NASA Lewis Research Center's $4 \mathrm{ft}$ Active Noise Control Fan (ANCF) shown in the schematic of figure 2. The ANCF uses a 16bladed variable-pitch rotor and can be configured with stator vanes to provide specific mode generation and propagation for the purpose of active noise control and more general aeroacoustics research. A unique feature on the ANCF is the direct attachment of the rotor centerbody to the rig support column, eliminating the need for struts, which could contaminate acoustic measurements. Additionally, an Inflow Control Device (ICD) allows for static testing. The combination of low tip speed $(\sim 400 \mathrm{ft} / \mathrm{sec})$ and the $4 \mathrm{ft}$ diameter generates fan tones of the same frequencies produced by full-size advanced engines. The ANCF is constructed of component spool pieces which can be replaced by ANC systems to be tested. A more complete description of the ANCF can be found in reference 1.

The primary measurement device on the ANCF is the Rotating Rake. The Rotating Rake is an implementation of a technique originally conceived by T.G. Soffrin [2] whereby a rake containing radially distributed pressure transducers rotates in the circumferential direction a precise fraction $(1 / 100)$ of the fan rotational speed. Since each circumferential acoustic mode is known to rotate at a unique speed relative to the rotor, a doppler shift is induced in the moving rake reference frame which enables the modes to be separated by frequency. Further reduction of the datainto radial modes is accomplished through a least squares curve fit to the Bessel function radial profiles. References 3 and 4 document the mode measurement technique and its implementation. Inlet and exhaust modes are measured at the inlet entrance and nozzle exit respectively, as shown in figure 2 .

The ANCF is located in the NASA LeRC's Aeroacoustic Propulsion Laboratory (APL), a hemispherical anechoic (to $125 \mathrm{~Hz}$.) test facility. Farfield measurements are taken from 28 microphones at 40-50 feet in the ANCF horizontal plane. The SPL data 
from these microphones are corrected to $40 \mathrm{ft}$ (10 fan diameters), standard day conditions.

\section{Test Conditions}

The 16 bladed fan rotor was set at a blade angle of $40 \mathrm{deg}$ and the stator was configured with 13 vanes spaced 2.25 in from the rotor blade trailing edge. This rotor/stator interaction produces an m order of 3 at BPF. Seven 0.25 in diameter rods were used just upstream of the rotor to generate a $m=2$ mode of fixed phase. The vanes were clocked in six different positions that were equally spaced over one vane passage. The last position is equivalent to the first so only 5 different positions are available with the last being a measure of repeatability. This generates an $m=3$ mode with a phase that advances $72 \mathrm{deg}$ for each position. For both $m=2 \& 3$ only the lowest radial order, $\mathrm{n}=0$ propagates. Both farfield microphone and induct mode data were obtained for three speeds, 1550, 1700, and $1850 \mathrm{rpm}$.

A second set of data was obtained using 8 rods instead of 7 . This produced a $\mathrm{m}=0$ mode while the 13 vanes still generated the $\mathrm{m}=3$ mode at the same $72 \mathrm{deg}$ interval of phase. The $m$ order of 0 has two radial orders propagating $(0,0 \& 0,1)$ in the inlet but only mode, $(0,0)$ in the exhaust.

\section{RESULTS AND DISCUSSION}

\section{Measured results for $m=2 \& 3$}

The farfield sideline directivity in terms of sound pressure level (SPL) at $40 \mathrm{ft}$ is shown in figure 3 for each of six vane positions. Variations of $10 \mathrm{~dB}$ at the same sideline angle are common in both the inlet and exhaust. Clocking the vanes through one blade spacing, 1/13th of $360 \mathrm{deg}$ in space (13 vane stator) represents $360 \mathrm{deg}$ of mode phase change for $m=3$. Since the $m=2$ mode has a fixed phase, a 360 deg phase change in the $m=3$ mode will produce a rotation of the complete interference pattern about the fan axis. Thus, for this case, one degree of stator movement produces 13 deg of change in the azimuthal pattern. This allows the azimuthal directivity to be measured by one fixed sideline array of microphones by rotating the stator and thus the azimuthal pattern in suitable increments.

The azimuthal directivity for two of the sideline microphones, 34 and $125 \mathrm{deg}$ is shown in polar form in figure 4. The data shown is the same as in figure 3. The angles chosen represent sideline locations near peak values for the inlet and exhaust respectively. This figure shows azimuthal variation of $12 \mathrm{~dB}$ or more with the peaks occurring about 70 deg apart. 
TABLE 1. Measured Modes for 7 Rods \& 13 Vanes at $1850 \mathrm{rpm}$, mode power, phase angle

\begin{tabular}{|c|c|c|c|c|c|c|c|c|c|c|}
\hline \multirow{3}{*}{$\begin{array}{c}\text { Vane } \\
\text { angle } \\
\text { deg }\end{array}$} & \multicolumn{5}{|c|}{ Inlet } & \multicolumn{5}{|c|}{ Exhaust } \\
\hline & \multicolumn{2}{|c|}{$\mathrm{m}=2$} & \multicolumn{3}{|c|}{$\mathrm{m}=3$} & \multicolumn{2}{|c|}{$\mathrm{m}=2$} & \multicolumn{3}{|c|}{$\mathrm{m}=3$} \\
\hline & $\begin{array}{c}\mathrm{PWL}, \\
\mathrm{dB}^{*}\end{array}$ & $\begin{array}{c}\text { phase } \\
\text { deg }\end{array}$ & $\begin{array}{c}\text { PWL, } \\
\text { dB }\end{array}$ & $\begin{array}{c}\text { phase } \\
\text { deg }\end{array}$ & $\begin{array}{l}\text { phase } \\
\text { (theory) }\end{array}$ & $\begin{array}{c}\text { PWL, } \\
\text { dB }\end{array}$ & $\begin{array}{l}\text { phase } \\
\text { deg }\end{array}$ & $\begin{array}{c}\text { PWL, } \\
\text { d B }\end{array}$ & $\begin{array}{l}\text { phase } \\
\text { deg }\end{array}$ & $\begin{array}{c}\text { phase } \\
\text { (theory) }\end{array}$ \\
\hline 0 & 115.0 & -73.9 & 114.4 & 170.0 & 170.0 & 117.2 & 12.5 & 121.4 & -179.8 & -179.8 \\
\hline 5.5 & 113.6 & -73.7 & 114.7 & 96.6 & 98.0 & 118.3 & 13.3 & 120.8 & 106.1 & 108.2 \\
\hline 11.1 & 113.8 & -63.1 & 113.6 & 44.9 & 26.0 & 118.8 & 11.4 & 120.1 & 40.8 & 36.2 \\
\hline 16.6 & 115.6 & -62.6 & 111.8 & -37.9 & -46.0 & 118.6 & 8.9 & 120.1 & -41.1 & -35.8 \\
\hline 22.2 & 115.8 & -71.1 & 113.0 & -120.1 & -118.0 & 118.1 & 10.8 & 121.0 & -113.6 & -107.8 \\
\hline 27.7 & 115.1 & -75.3 & 115.0 & 165.6 & 170.0 & 118.1 & 12.7 & 121.4 & -177.4 & -179.8 \\
\hline
\end{tabular}

${ }^{*}$ PWL is referenced to $10^{-12}$ watts

The mode measurements that correspond to figures 3 and 4 are shown in Table 1. The magnitude and phase of both the inlet and exhaust $m=2$ modes stays nearly constant as the vanes are clocked. The phase of the $m=3$ modes change by approximately $72 \mathrm{deg}$ as was expected. The magnitude of $m=3$ in the exhaust remains nearly constant as would be expected. The magnitude of the inlet $m=3$ mode shows a more significant variation with vane angle. This may be due to a small exhaust reflection traveling back through the inlet. This would only occur when the inlet mode level is sufficiently lower than the exhaust mode. In such a case, even a small reflection in the exhaust can be significant when compared to a weaker inlet mode. These results indicate that the phase of the $m=3$ modes was the only parameter changing when the vanes were clocked with the exception of a $\pm 1.6 \mathrm{~dB}$ magnitude change of $m=3$ in the inlet. The changes in the magnitude of $m=3$ in the inlet at $1700 \mathrm{RPM}$ where larger, $\pm 3.5 \mathrm{~dB}$ while at $1550 \mathrm{RPM}$ there was a variation of less than $\pm 0.5 \mathrm{~dB}$. These variations in the magnitude of $m=3$ corresponds to the differences in the inlet to exhaust levels for $m=3$, ie. the larger the exhaust relative to the inlet level the larger the inlet variation.

A typical measured modal structure for both the inlet and exhaust is shown in figure 5 in the form of a 3-D bar graph. The mode power is shown on the vertical axis while the circumferential order, $m$ and radial order, $n$ are shown on the other axes. The back row represents the total power in the $m$ order. The inlet mode structure shows that $m=2 \& 3$ are nearly equal in power and $11 \mathrm{~dB}$ above any other mode. This $11 \mathrm{~dB}$ difference is on the low side and could limit the range of the interference pattern in the azimuthal direction. The exhaust modal structure has the same $m=2 \&$ 3 modes, again of nearly equal power, but $5 \mathrm{~dB}$ higher than the inlet modes. The signal to noise ratio in the exhaust in terms of the next highest mode is over $18 \mathrm{~dB}$, 
which is much better than in the inlet. Experience has shown that when rods are used to generate interaction modes there are more modes generated that are extraneous to the rod and blade count then in a rotor/stator interaction case. These higher levels of extraneous modes may be related to the turbulent nature of the rod wakes.

A more global and possibly revealing way to examine the farfield data is shown in figure 6a) where the azimuthal and the sideline angles are plotted against SPL. Only part a) of this figure will be discussed here and part b) will be discussed in a later section. This contour plot shows a complicated distribution of farfield SPL. Many of the peaks and valleys at sideline angles between 50 and 120 deg are probably a result of inlet and exhaust interference. There is a major peak in the inlet at an azimuthal angle near $220 \mathrm{deg}$, while the exhaust peak is near $144 \mathrm{deg}$. The farfield power for each azimuthal angle measured, assuming axisymmetric directivity, is shown on the right side of the plot. A $5.7 \mathrm{~dB}$ variation in power is observed here. This is large considering that power is an integrated value and thus tends to be less subject to variation. Figures 7a) and $8 \mathrm{a}$ ) show these farfield directivty maps at the two lower speeds. The peaks for both the inlet and exhaust directions occur at different azimuthal angles at different speeds. The lower speeds seem to show more inlet/exhaust interference than the highest speed as indicated by the more numerous vertical patterns. The 1550 RPM data shows some indication of exhaust interference as far forward as a sideline angle of $30 \mathrm{deg}$. It is a little surprising that exhaust radiated noise would have sufficient strength at an angle $30 \mathrm{deg}$ from the inlet axis to cause noticeable interference with inlet noise. The farfield measurements were taken at a distance of 10-12 fan diameters where much of the coherence between the inlet and exhaust noise appears to be preserved. At larger distances the inlet/exhaust interference pattern would start to wash out.

In any case, there are variations in the azimuthal direction as high as 15 to $20 \mathrm{~dB}$ which would have been ignored if the measurements were made at only one vane angle or azimuthal angle.

\section{Computation of Farfield Radiation}

The noise radiation to the far-field may be computed using analytical methods or finite volume/finite element techniques. The finite element technique has the advantage of modeling the geometry accurately. The finite element technique and computer codes developed by Eversman and Danda Roy [5,6], and applied to modern turbofans by Topol et. al. $[7,8]$ are used in the present study. A brief description of the computational techniques for the inlet and aft radiation problem is given below.

\section{Inlet Radiation}

The turbofan inlet is assumed to be axisymmetric and the computational domain is reduced to a two-dimensional meridional plane. Eversman and Danda Roy [6] solve the radiation problem in this domain using a finite element technique. 
The propagation in the duct and the radiation to the farfield are included in one model. The inlet flow is assumed irrotational. The sound source at the source plane (fan face) is modeled in terms of modal amplitudes. The input to the acoustic radiation problem is given in terms of specified value of incident modal amplitude in the present study. The near-field region is modeled using conventional isoparametric finite elements. Wave envelope elements are used in the farfield, assuming that the sound field there approximates that produced by a point source at the origin. It is assumed that only outgoing waves exist at the farfield boundary. A Sommerfeld radiation condition for a monopole in a uniform flow is applied there. With the wave envelope elements in the farfield the entire radiation field can be modeled with a relatively small number of elements. The solution to the finite element system is obtained using a frontal solution method. Further details of the finite element formulation and the solution procedure may be found in reference 5 .

\section{Aft Radiation}

The equations governing the acoustic field of the aft radiation are the same as that of the inlet. However, the jet shear layer introduces complication for the computation of the mean flow. The shear layer is modeled as though the duct is extended several duct radii beyond the exit plane. Along the streamline representing the shear layer a connectivity for potential flow is constructed (in the finite element mesh generation) which allows for a discontinuity in velocity potential. Beyond the extended duct region the velocity potential is allowed to be continuous. The steady mean flow treated as a duct flow as described is allowed to mix on a potential flow basis with the external flow beyond the extended region. The extent of the extended duct region can be varied. It is chosen so as to provide sufficient distance for full effect on acoustic radiation and long enough to move the rather artificial mixing region away from the important part of the acoustic field [6]. This kind of shear layer treatment of the shear layer is found to work reasonably well for the moderate Mach number cases considered in this report. Further details of the formulation of the aft radiation problem and the solution method may be found in reference 6 .

\section{Method of Computation}

The inlet and exhaust radiation are computed separately as indicated above. The input at the source plane is the measured in-duct modal amplitudes at the measurement stations. The radiation field is computed one circumferential mode at a time and the complex acoustic pressures are combined to get the resultant field. For the axisymmetric case, the radiation from ANC fan ducts have been computed and reported in reference [9]. Comparisons of the computed results with the measurements were reported in [1 and 11]. For the present non-axisymmetric case, we consider one plane at a time and use the measured in-duct modal amplitudes to compute the far-field levels corresponding to that azimuthal plane. The process is repeated to get the complete azimuthal variation. 


\section{Comparison of Computed and Measured Farfield Directivites}

Figures $6 b)-8 b$ ) show a comparison where the complex value of the induct modes are used as input to the code for each vane angle (azimuthal angle) measured. The inlet and exhaust were modeled separately and joined at a sideline angle of 90 deg so that the interference patten caused by the coherence of the two sources would not be expected to appear in the code results. The location and level of the major inlet and exhaust peaks seems to be well predicted by the code. It is more difficult to compare the code predictions to the data at the lower speeds due to what appears to be inlet/exhaust interference. For example, at 1550 RPM there are at least three peaks in the inlet radiation in the sideline direction. This can mask the interference pattern in the azimuthal direction caused by the inlet $m$ orders 2 and 3 . An attempt to predict the measured inlet/exhaust interference pattern using the code was made with little success. Many problems such as: maintaining a common phase angle reference for the inlet and exhaust mode measurements, not including levels of other modes (see fig 5), preserving phase accuracy in the code from induct to the farfield, and projecting the pattern to a constant radius when the microphones are not on a constant radius, make this a difficult task.

The code predictions indicates very low pressure levels near the inlet axis, while the data shows higher levels. This is a result of a low level of the mode $(0,0)$, the plane wave, which is the only mode that propagates on axis. Another characteristic of the plane wave is it has the highest farfield pressure level for a given mode power making it very noticeable. At any place where the code predicts low levels, modes other then $m=2 \& 3$ might provide a noise floor. This is particularly true in the inlet where the largest extraneous mode is only $11 \mathrm{~dB}$ below the interaction modes.

\section{Measured Results For $m=0$ \& 3}

The farfield directivity maps for all three speeds for an 8 rod 13 vane $(m=0 \& 3)$ configuration is shown in figure 9 . The most noticeable feature in these plots is the three lobed pattern in the azimuthal direction. This results from the $\mathrm{m}$ order difference of three between the modes. The azimuthal pattern in the inlet is somewhat less dramatic then in the $m=2 \& 3$ case. This is for the most part, a result of the large difference in the sideline angle at which the peak radiation occurs for the two modes. It should be noted that for $m=0$ there are two propagating radial orders, $\mathrm{n}=0$ \& 1 in the inlet only, unlike all the other modes in this paper. The levels of the $\mathrm{n}=1$ radial are 7 to $11 \mathrm{~dB}$ below the $\mathrm{n}=0$ mode. The power levels shown on the right side of the plots indicate less variation (error due to the axisymmetric assumption) than in the $m=2 \& 3$ case.

The large cancellations near a sideline angle or $75 \mathrm{deg}$ at $1850 \mathrm{RPM}$ appear to be inlet/exhaust interference. At the lower speeds, as in the $m=2 \& 3$ case, the inlet/exhaust interference seems to effect the inlet further forward and in more sideline locations. 


\section{CONCLUDING REMARKS}

The large differences in sideline directivity observed at different azimuthal angles indicate that current practice of assuming axisymmetry my be erroneous in many cases. In this investigation a worst case scenario may have been examined, since both modes have similar power. But, even when modes of significant power difference are present there can be some locations in the farfield where their levels are equal and strong interactions will occur. Without knowledge of the modal content it could be dangerous to assume axisymmetry in the farfield.

It now appears that the complete (3-D) tone radiation pattern might be predicted from modal measurements through the use of a propagation code. The code provides a reasonable prediction of the farfield azimuthal pattern caused by the two $\mathrm{m}$ orders, but was unable to accurately predict the inlet/exhaust interference pattern. The inlet/exhaust interference is an important feature, at least at a distance of 10 diameters from the fan. It is conceivable that this mode measurement technique and code may some day replace the conventual semicircular microphone array and axisymmerty assumption when tone noise is the major concern. Currently however, in cases where multiple circumferential modes are present it might be wise to vary the phases of all the modes to predict a band of directivity curves representing the possible range of azimuthal variation to be expected.

Future work in the area of measuring the phases of inlet and exhaust modes on a common reference and implementation of the code to predict inlet/exhaust interference more accurately and over a larger angular range is planed. In addition, the azimuthal effect of modes extraneous to rotor/stator interaction will be investigated using measured mode data from high speed fan models.

\section{REFERENCES}

1) Heidelberg, L.J., Hall, D.G., Bridges, J.E., and Nallasamy, M., "A Unique Ducted Fan Test Bed for Active Noise Control and Aeroacoustics Research," AIAA 96-1740 (NASA TM-107213). May 1996.

2) Cicon, D.E., Sofrin, T.G., and Mathews, D.C., "Investigation of Continuously Traversing Microphone System for Mode Measurement," NASA CR-168040, Nov. 1982.

3) Heidelberg, L.J. and Hall, D.G., "Acoustic Mode Measurements in the Inlet of a Model Turbofan Using a Continuously Rotating Rake," Journal of Aircraft, Vol. 32, No. 4, 1995, pp. 761-767.

4) Hall,D., Heidelberg, L., Konno, K. "Acoustic Mode Measurements in the Inlet of a Model Turbofan Using a Continuously Rotating Rake: Data Collection/Analysis Techniques," AIAA-93-0599 (NASA TM-105936). January, 1993. 
5) Eversman, W. and Danda ROY, I., "Ducted Fan Acoustic Radiation including the Effects of Non-Uniform Mean Flow and Acoustic Treatment," AIAA 93-4424, 1993.

6) Eversman, W., "Aft Fan Duct Acoustic Radiation," CEAS/AIAA 95-155, 1995.

7) Philbrick, D.A., and Topol, D.A., "Development of a Fan Noise Design System, Part 1: System Design and Source Modeling." AIAA 93-4415, 1993.

8) Topol, D.A., "Development of a Fan Noise Design System, Part 2: Far-field Radiation and System Evaluation,' AIAA 93-4416, 1993.

9) Nallasamy, M., "Noise Radiation From Fan Inlet and Aft Ducts", AIAA 96-1769, 1966.

11) Sutliff, D.J., Nallasamy, M. and Heidelberg, L.J., "Baseline Acoustic Levels of the NASA Active Noise Control Fan Rig", AIAA 96-1745, May 1996. 


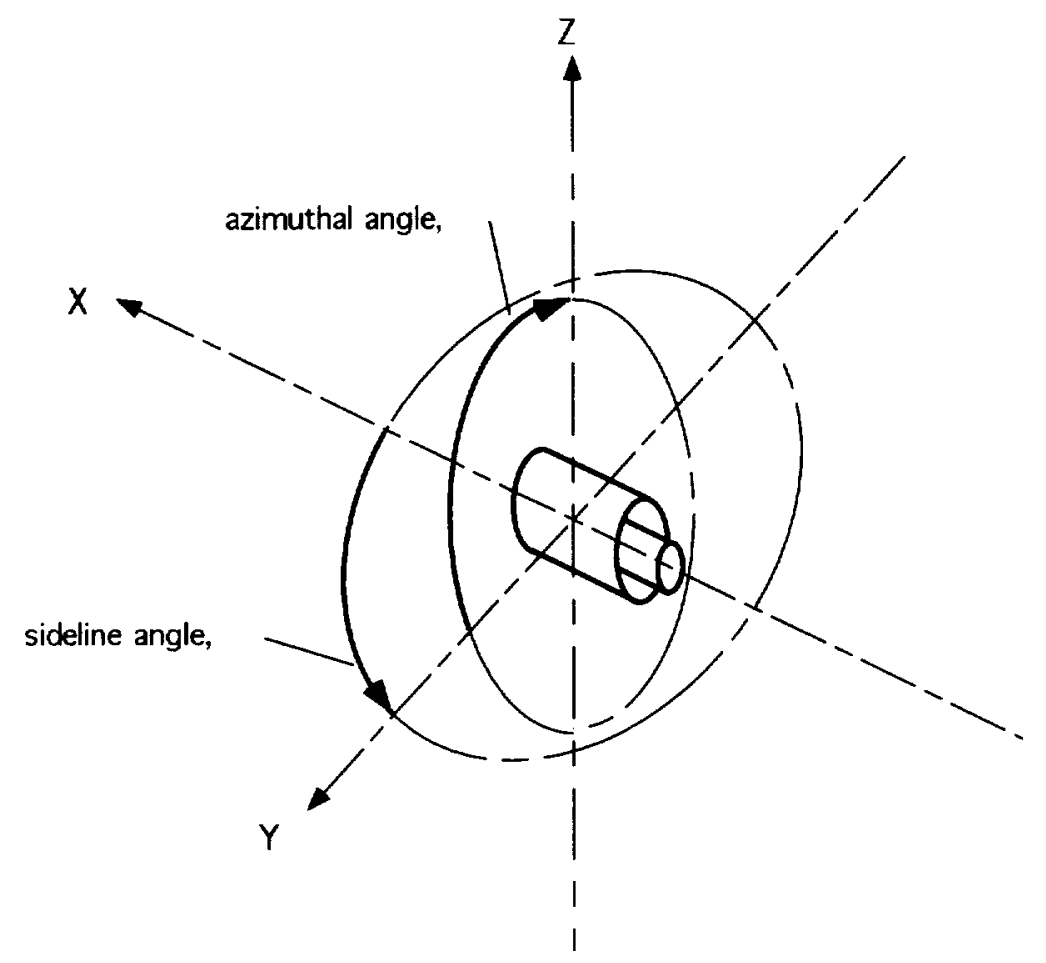

Figure 1. Angular references for fan directivity

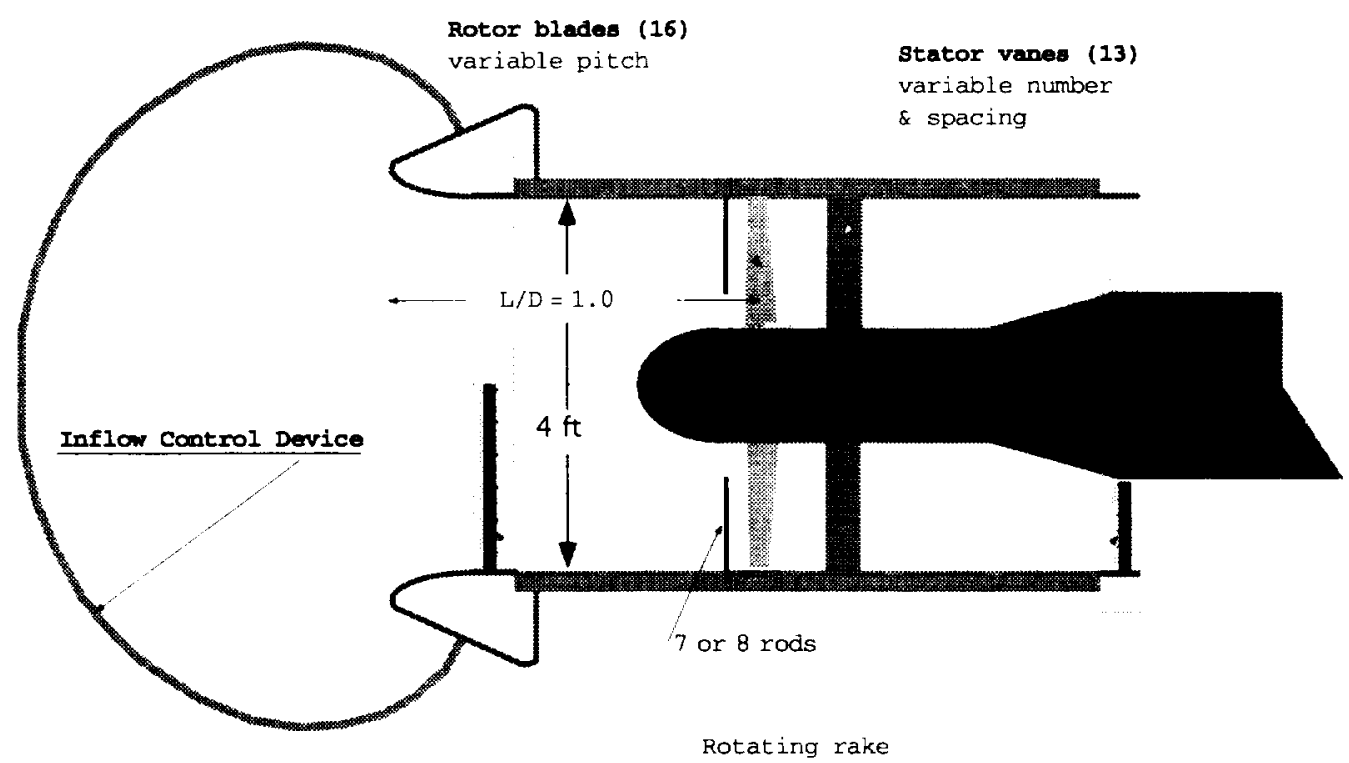

Figure 2. Schematic of Active Noise Control Fan showing Rotating Rake Measurement Locations 


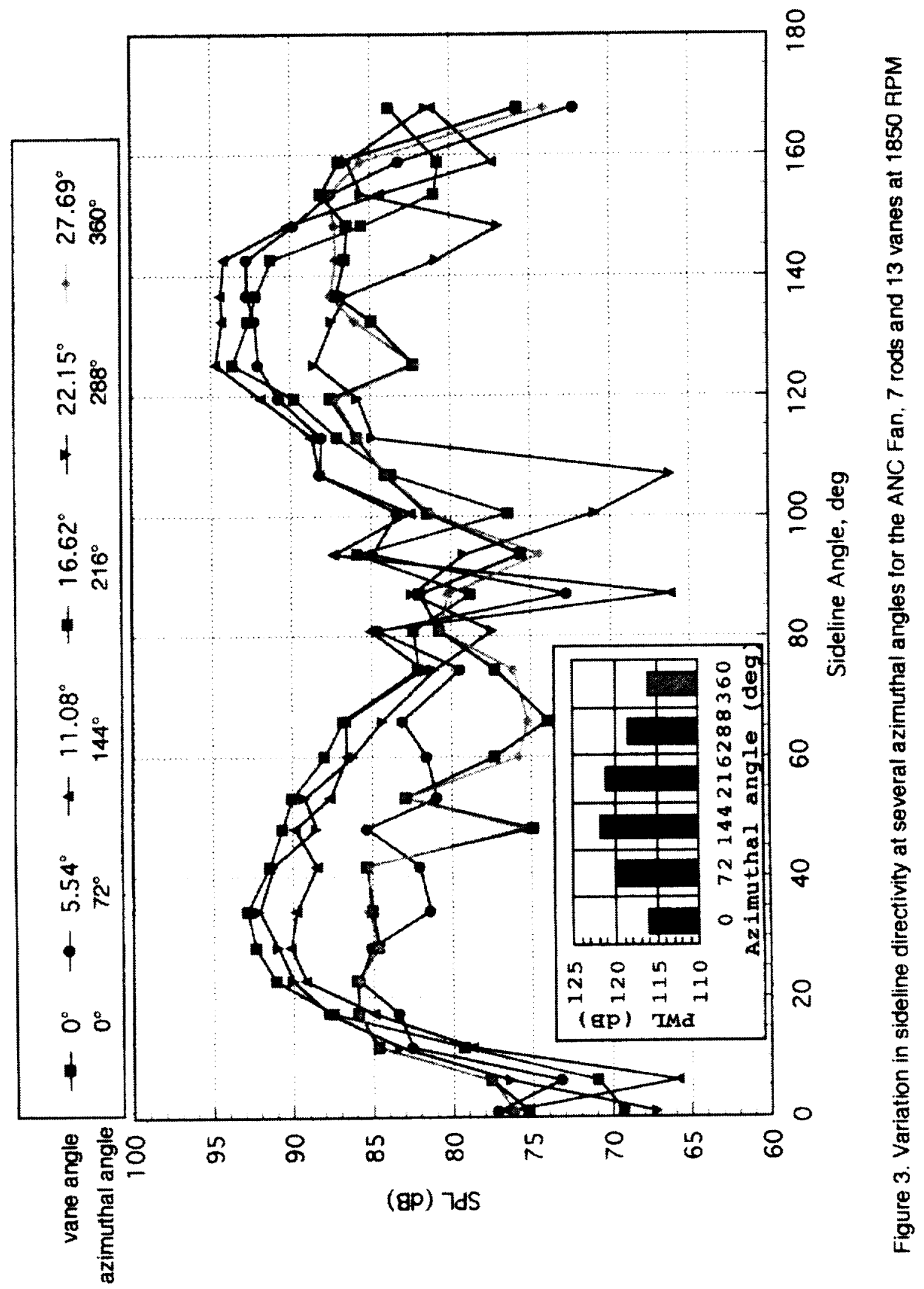




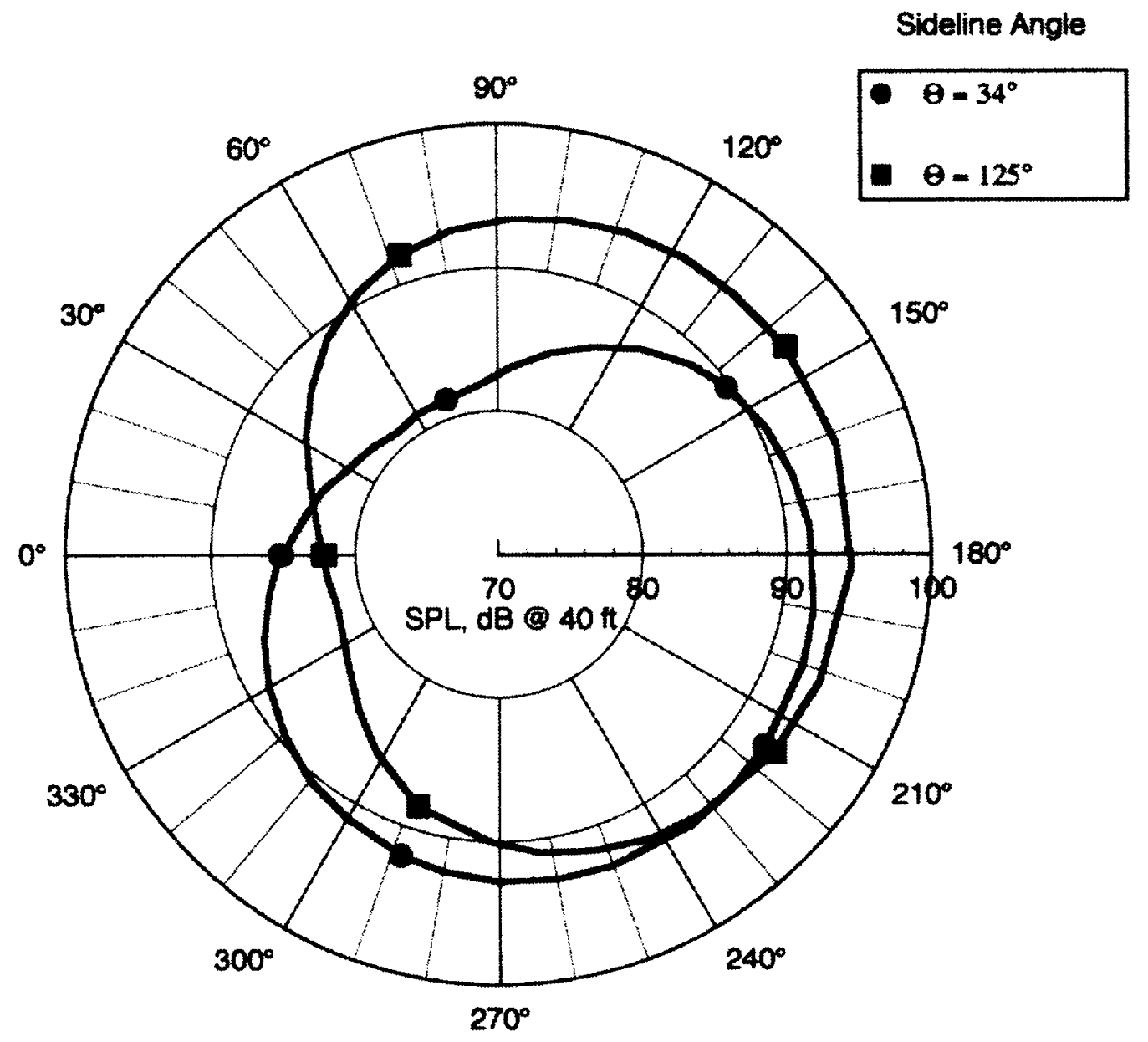

Azimuthal Angle

Figure 4. Polar Plot of Azimuthal Directivity for 7 Rods and 13 Vanes $(m=283), 1850$ RPM. 


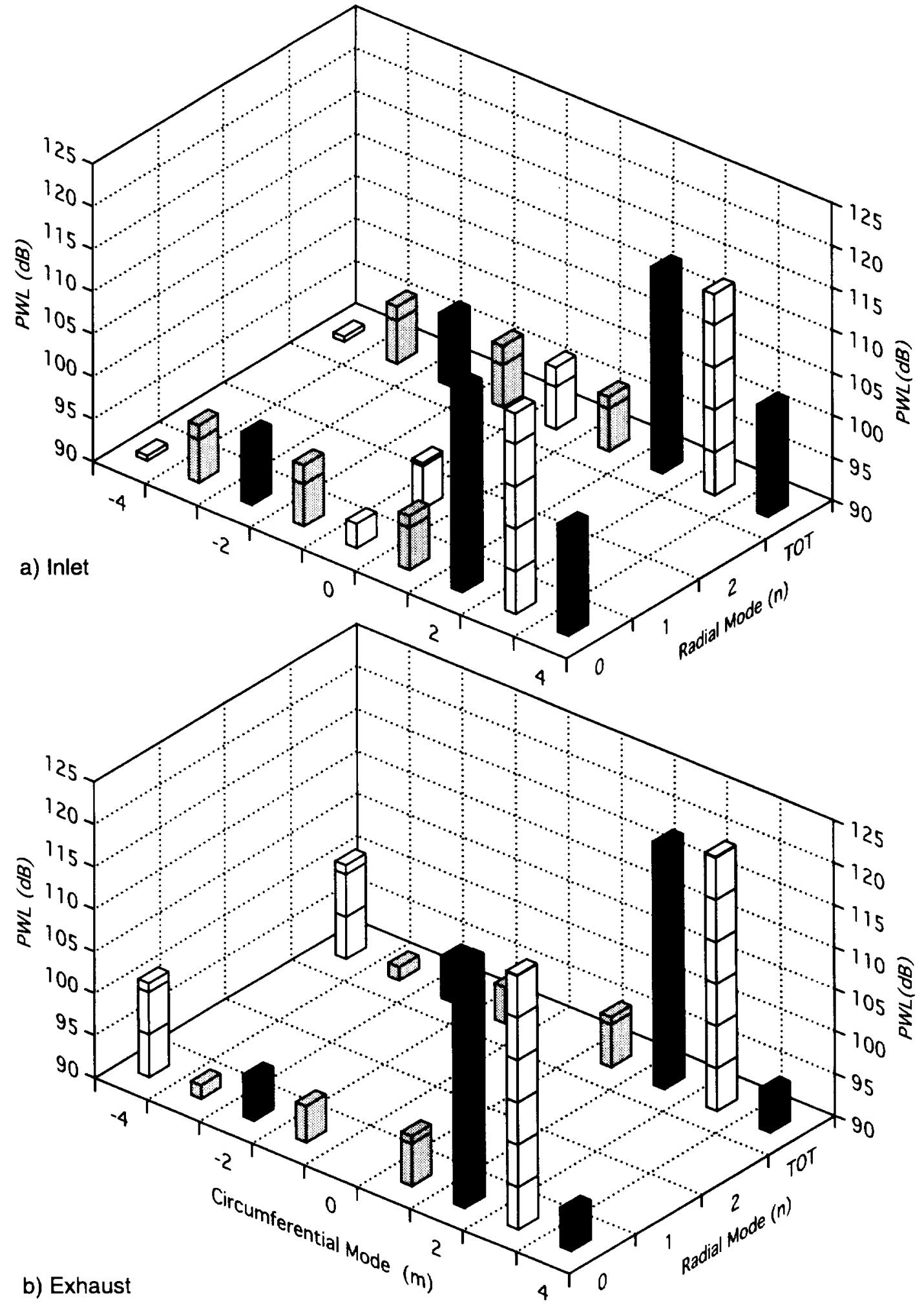

Figure 5. Typical BPF Modal Structure for 7 Rods and 13 Vanes, 1850 RPM, Vane angle $11 \mathrm{deg}$ 
$P W L, d B$

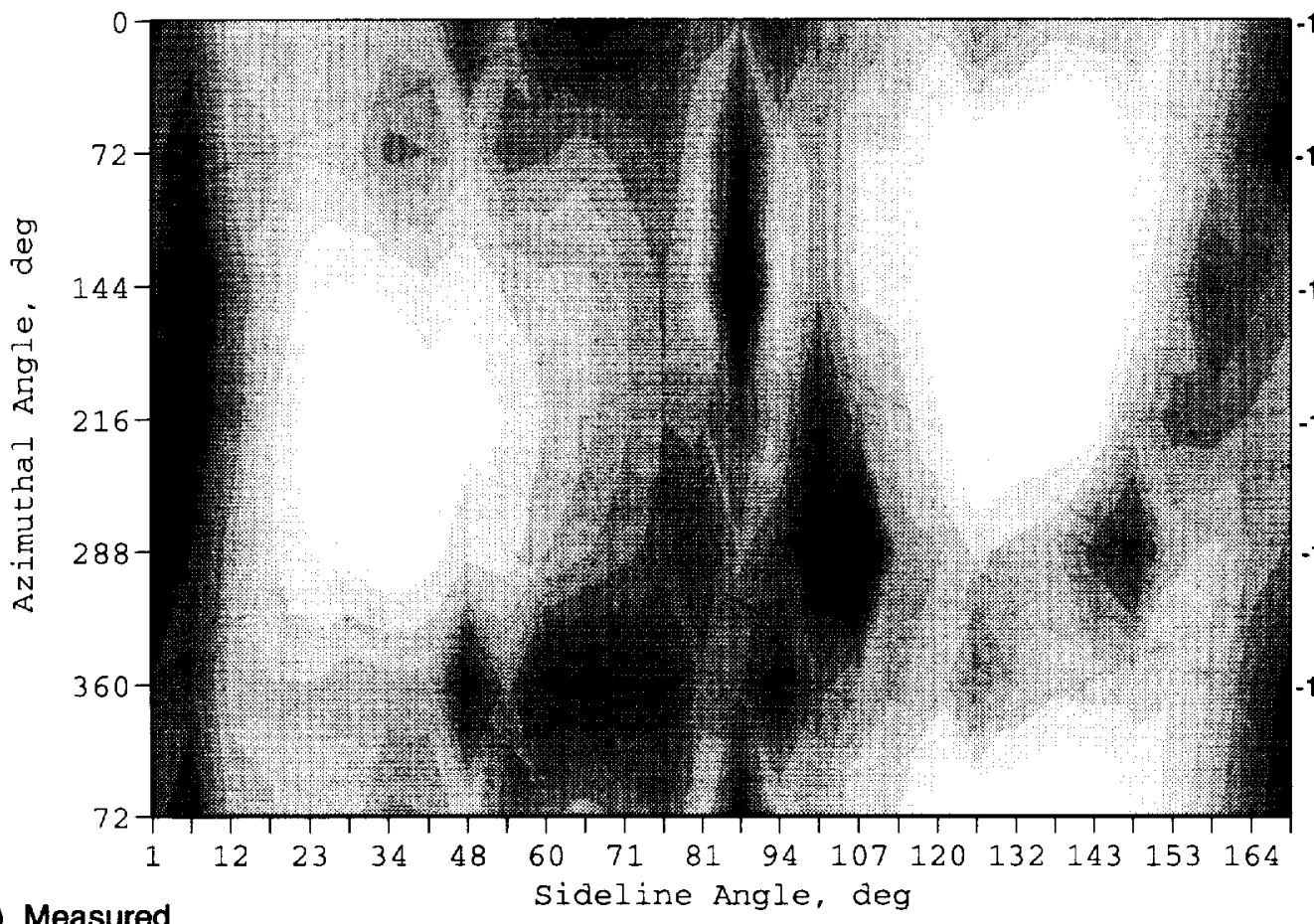

$-116.1$

$-119.8$

$-121.8$

$-121.0$

Measured

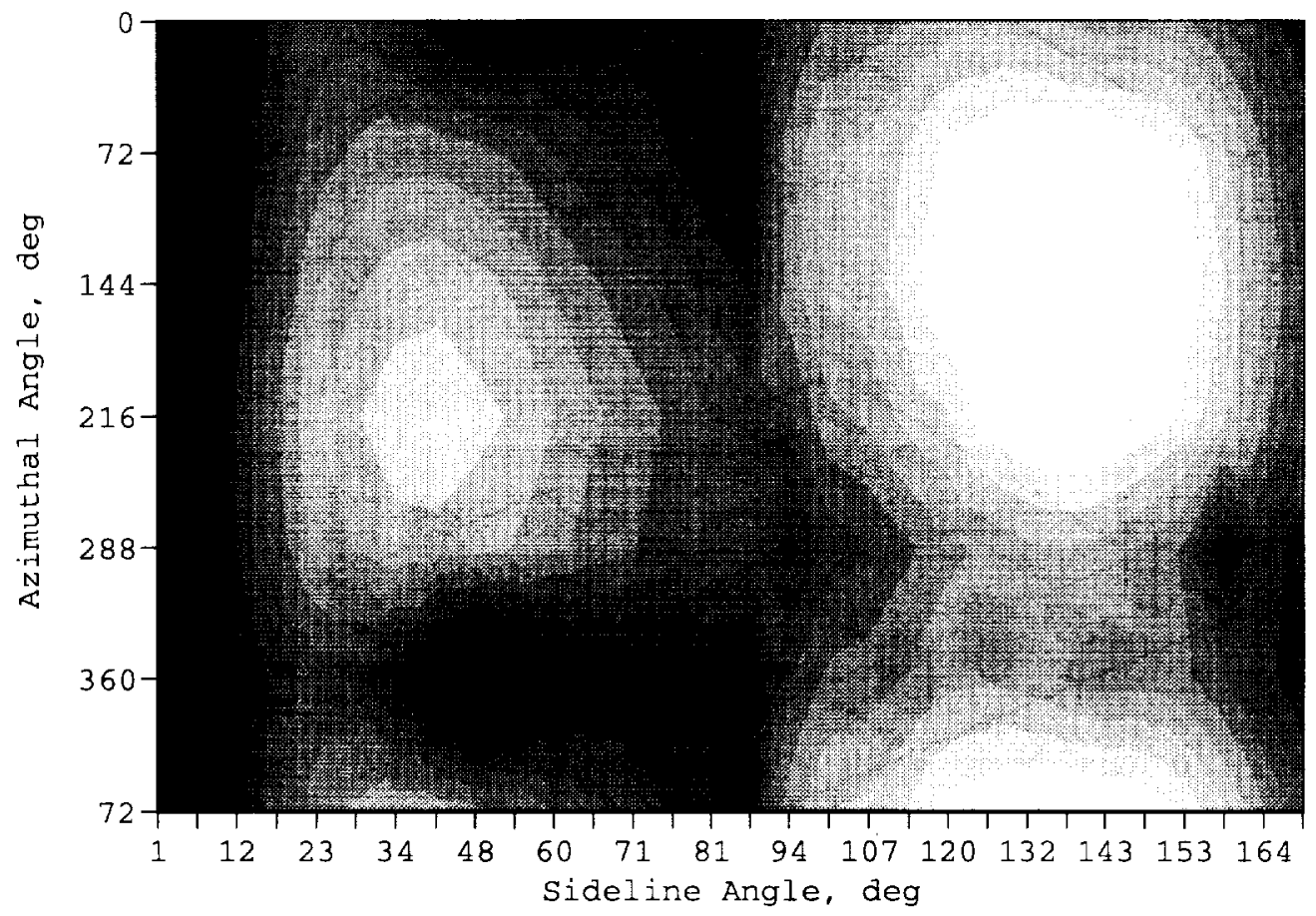

SPL @ 40ft, dB $-118.4$

$-116.1$

\begin{tabular}{|r|}
\hline 96 \\
94 \\
92 \\
90 \\
88 \\
86 \\
84 \\
82 \\
80 \\
78 \\
76 \\
74 \\
72 \\
70 \\
68 \\
66 \\
64 \\
62 \\
60 \\
\hline
\end{tabular}

b) Code predictions, no inlet/exhaust interference

Figure 6. Comparison of measured and code predictions of far field directivity maps for modes, $(2,0 \& 3,0)$ at 1850 RPM 


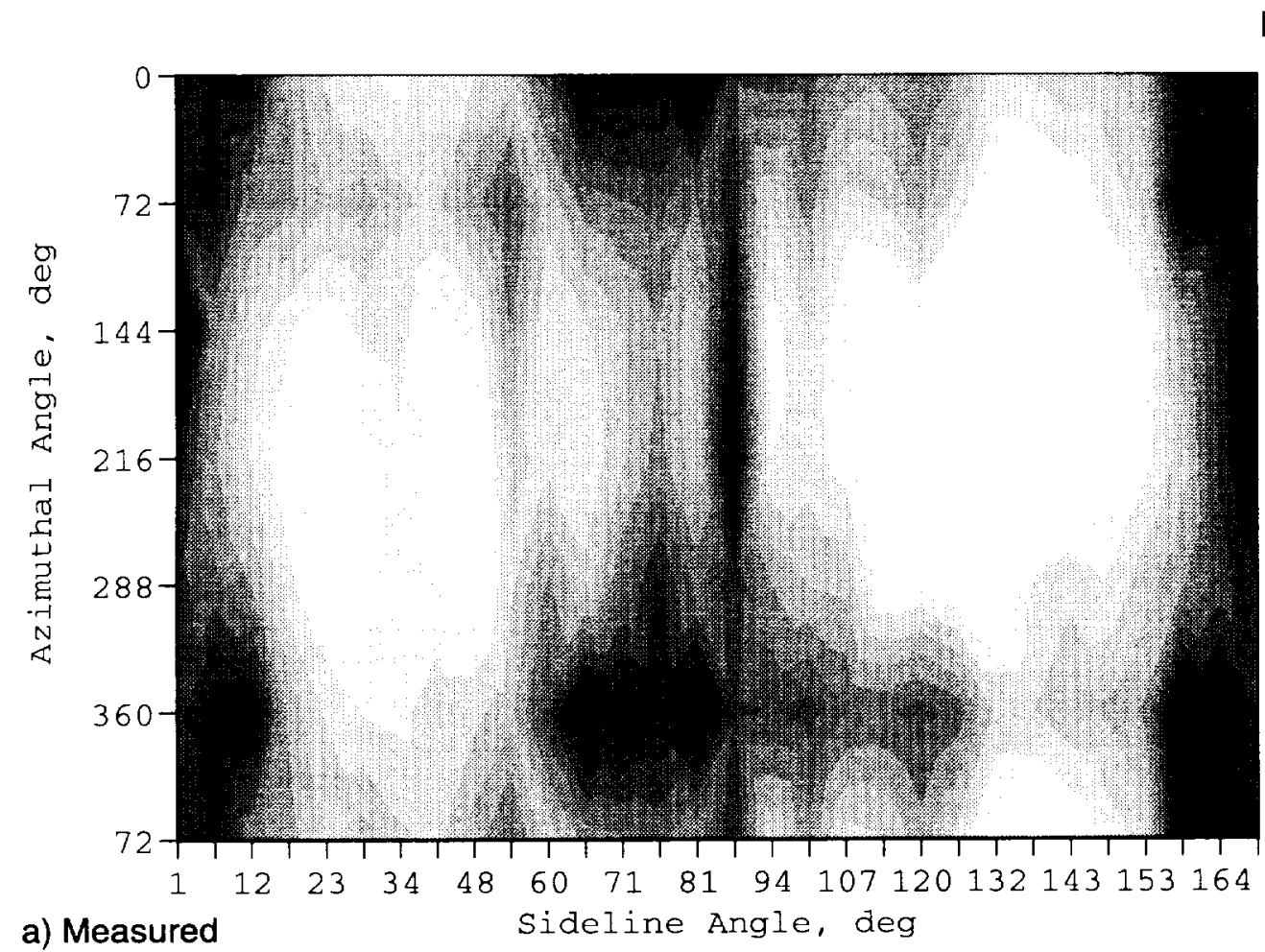

PWL, dB

$-113.0$

$-115.9$

$-120.1$

$-120.7$

SPL@ $40 \mathrm{ft}, \mathrm{dB}$

$-118.0$

$-113.0$
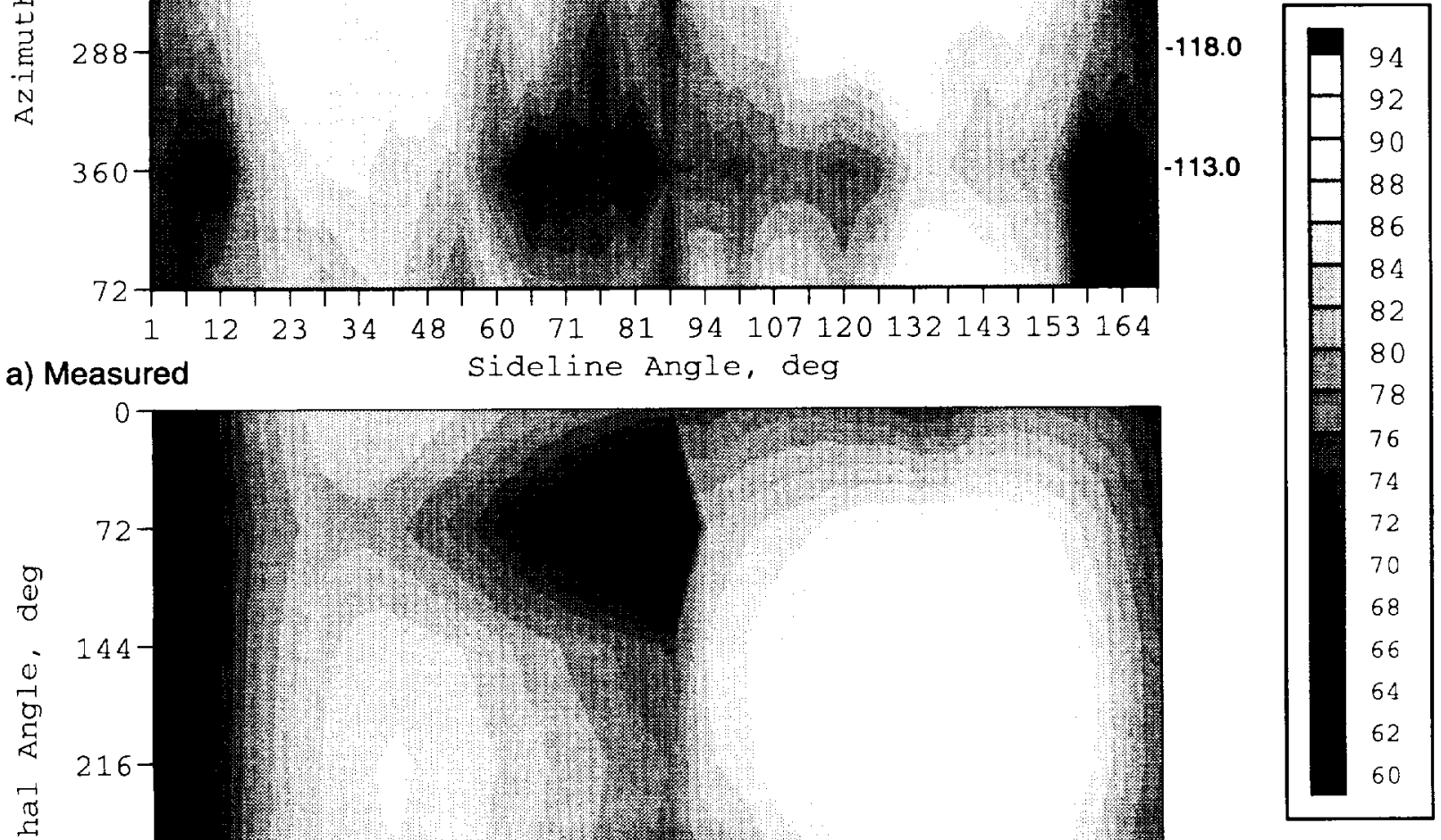

b) Code predictions, no inlet/exhaust enterference

Figure 7. Comparison of measured and code predictions of farfield directivity maps for modes $(2,0 \& 3,0)$ at 1700 RPM 


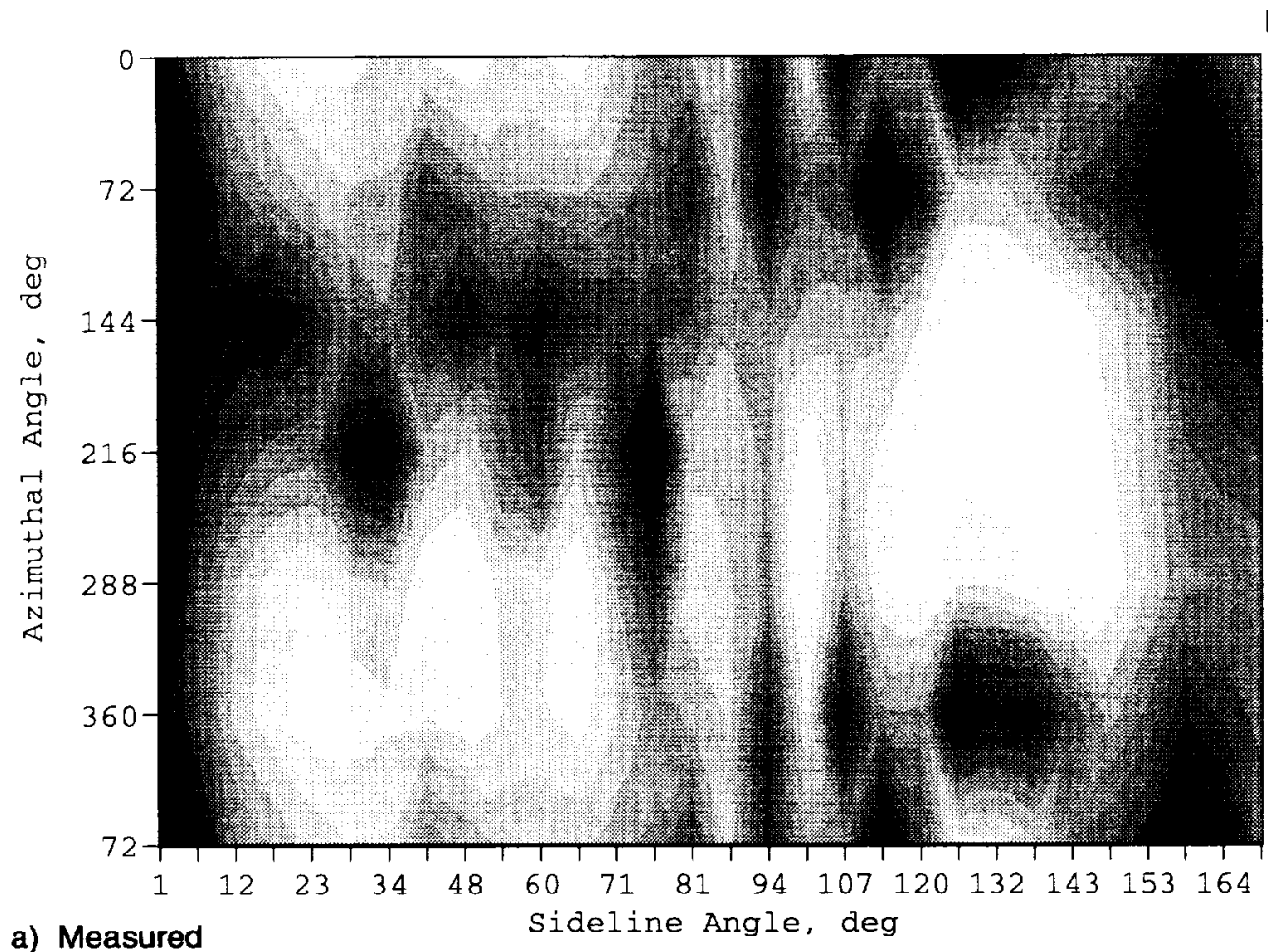

PWL, dB

$-115.6$

$-112.9$

$-115.6$

$-117.2$

SPL $40 \mathrm{ft}, \mathrm{dB}$

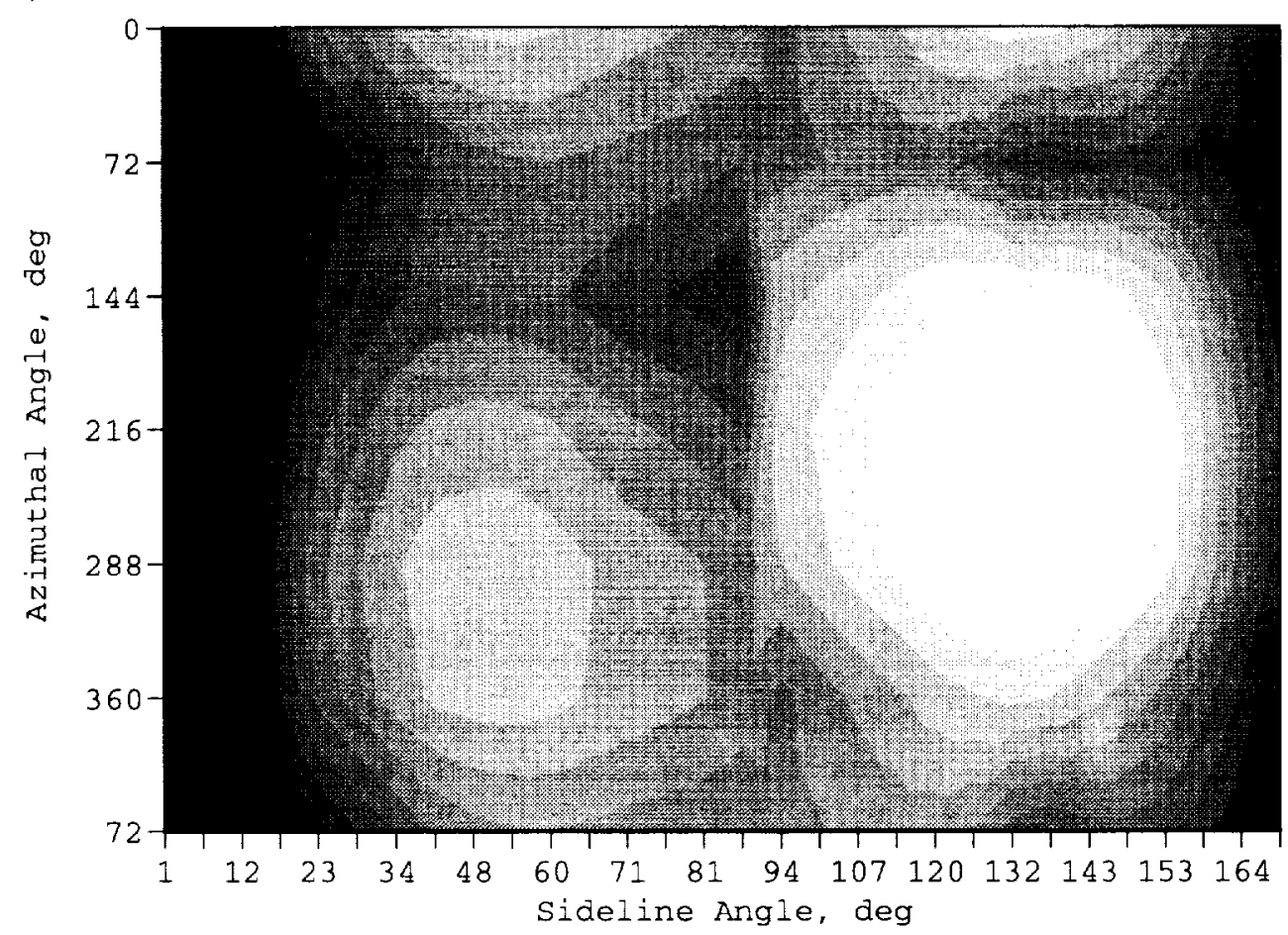

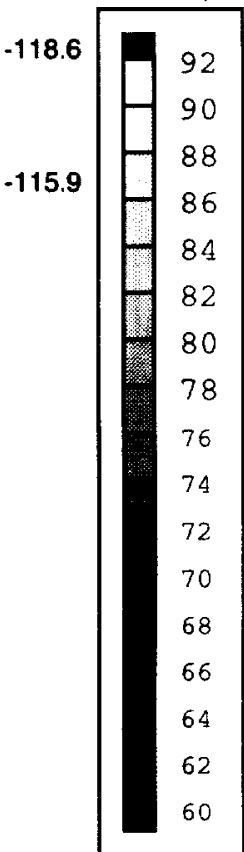

b) Code predictions, no inlet/exhaust interference

Figure 8. Comparison of measured and code predictions of farfield directivity maps for modes $(2,0 \& 3,0)$ at 1550 RPM 


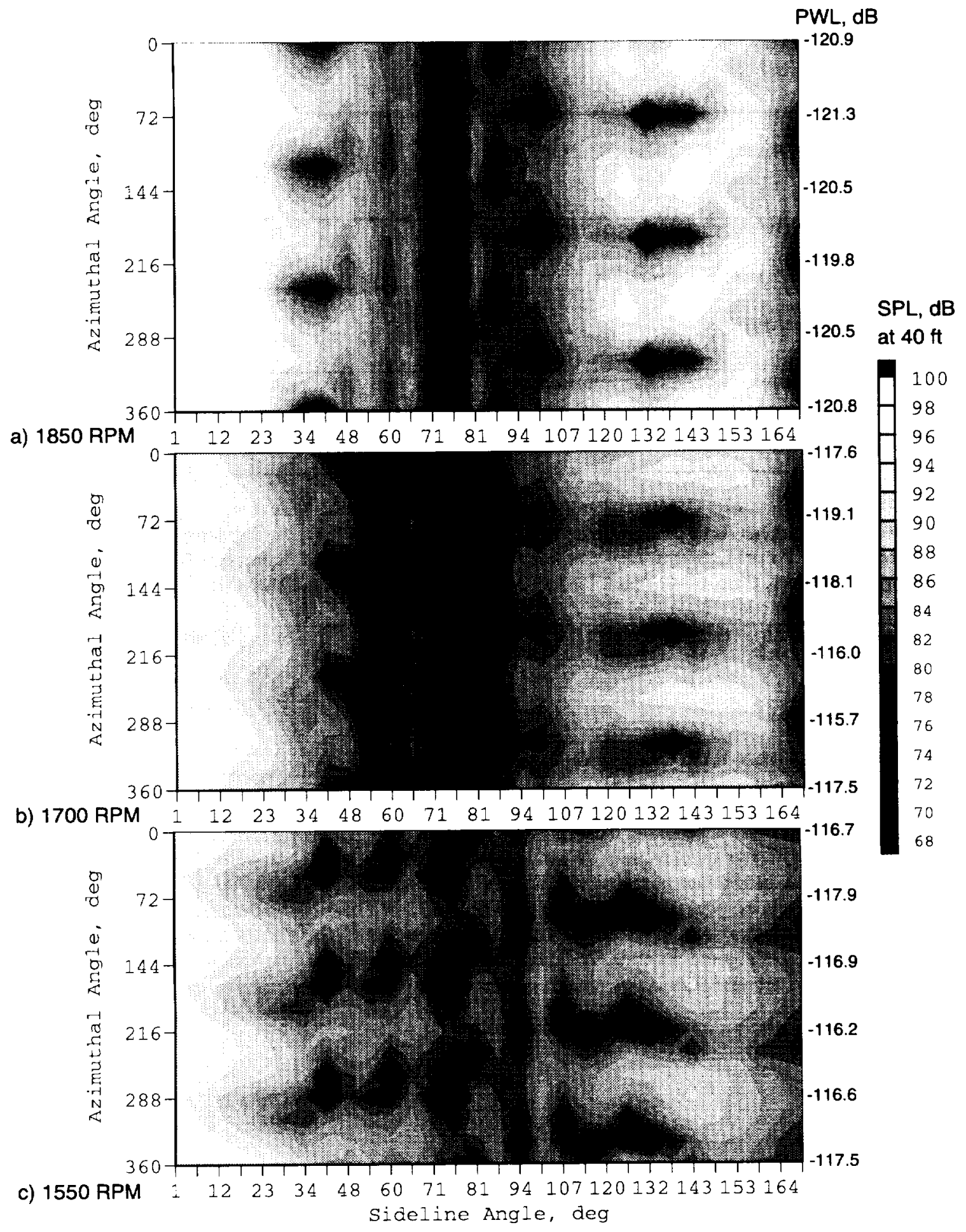

Figure 9. Farfield Directivity Map for 8 Rods and 13 Vanes $(m=0 \& 3)$ 
Public reporting burden for this collection of information is estimated to average 1 hour per response, including the time for reviewing instructions, searching existing data sources, gathering and maintaining the data needed, and completing and reviewing the collection of intormation. Send comments regarding this burden estimate of any ather aspect of this collection of information, including suggestions for reducing this burden, to Washington Headquarters Services, Directorate for Information Operations and Reports. 1215 Jefferson Davis Highway, Suite 1204. Arlington, VA 22202-4302, and to the Otfice of Management and Budget, Paperwork Feduction Project (0704-0188), Washington, DC 20503.

\begin{tabular}{|l|c|c|}
\hline 1. AGENCY USE ONLY (Leave blank) & $\begin{array}{r}\text { 2. REPORT DATE } \\
\text { May } 1997\end{array}$ & $\begin{array}{r}\text { 3. REPORT TYPE AND DATES COVERED } \\
\text { Technical Memorandum }\end{array}$ \\
\hline
\end{tabular}

4. TITLE AND SUBTITLE

Azimuthal Directivity of Fan Tones Containing Multiple Modes

6. AUTHOR(S)

Laurence J. Heidelberg, Daniel L. Sutliff, and M. Nallasamy

7. PERforming oRganization NAME(S) AND ADDRESS(ES)

National Aeronautics and Space Administration

Lewis Research Center

Cleveland, Ohio 44135-3191

9. SPONSORINGMONITORING AGENCY NAME(S) AND ADDRESS(ES)

National Aeronautics and Space Administration

Washington, DC 20546-0001

11. SUPPLEMENTARY NOTES

Prepared for the 3rd Aeroacoustics Conference cosponsored by the American Institute of Aeronautics and Astronautics and the Confederation of European Aerospace Societies, Atlanta, Georgia, May 12-14, 1997. Laurence J. Heidelberg, NASA Lewis Research Center; Daniel L. Sutliff, AYT Corporation, Brook Park, Ohio; M. Nallasamy, NYMA Inc., 2001 Aerospace Parkway, Brook Park, Ohio 44142 (work funded by NASA Contract NAS3-27186). Responsible person, Laurence, J. Heidelberg, organization code 5940 (216) 3859.

12a. DISTRIBUTION/AVAILABILITY STATEMENT

Unclassified - Unlimited

Subject Categories 07 and 71

This publication is available from the NASA Center for AeroSpace Information, (301) 621-0390.

13. ABSTRACT (Maximum 200 worde)

The directivity of fan tone noise is generally measured and plotted in the sideline or flyover plane and it is assumed that this curve is the same for all azimuthal angles. When two or more circumferential (m-order) modes of the same tone are present in the fan duct, an interference pattern develops in the azimuthal direction both in the duct and in the farfield. In this investigation two m-order modes of similar power were generated in a large low speed fan. Farfield measurements and a finite element propagation code both show substantial variations in the azimuthal direction. Induct mode measurement were made and used as input to the code. Although these tests may represent a worst case scenario, the validity of the current practice of assuming axisymmetry should be questioned.

14. SUBJECT TERMS

Ducted fans; Engine noise; Acoustic measurement; Aircraft noise; Aeroacoustics

\begin{tabular}{l|c}
\hline $\begin{array}{l}\text { 17. SECURITY CLASSIFICATION } \\
\text { OF REPORT } \\
\text { Unclassified }\end{array}$ & $\begin{array}{c}\text { 18. SECURITY CLASSIFICATION } \\
\text { OF THIS PAGE } \\
\text { Unclassified }\end{array}$ \\
\hline
\end{tabular}

NSN 7540-01-280-5500
8. PeRforming oRganization

E-10750
NASA TM-107464

AIAA-97-1587 12b. DISTAIBUTION CODE 